\title{
Risk factors for prospective increase in psychological stress during COVID-19 lockdown in a representative sample of adolescents and their parents - ERRATUM
}

Kerstin Paschke, Nicolas Arnaud, Maria Isabella Austermann and Rainer Thomasius

\section{Key words}

Psychological stress; COVID-19 lockdown; testing; adolescents; parents; risk factors; corrigendum.

\section{Copyright and usage}

(c) The Author(s), 2021. Published by Cambridge University Press on behalf of the Royal College of Psychiatrists. This is an Open Access article, distributed under the terms of the Creative Commons Attribution licence (http://creativecommons.org/licenses/by/4.0/), which permits unrestricted re-use, distribution, and reproduction in any medium, provided the original work is properly cited.

https://doi.org/10.1192/bjo.2021.49, Published online by Cambridge University Press, 03 May 2021
This article was published with an error in Figure 2 where the symbols for adolescents and parents were accidentally switched around. The publisher apologises for this mistake and the correct version of the figure is below.

\section{Reference}

Paschke $\mathrm{K}$, Arnaud N, Austermann $\mathrm{Ml}$ and Thomasius R. Risk factors for prospective increase in psychological stress during COVID-19 lockdown in a representative sample of adolescents and their parents. BJPsych Open 2021; 7(3): e94.

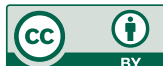

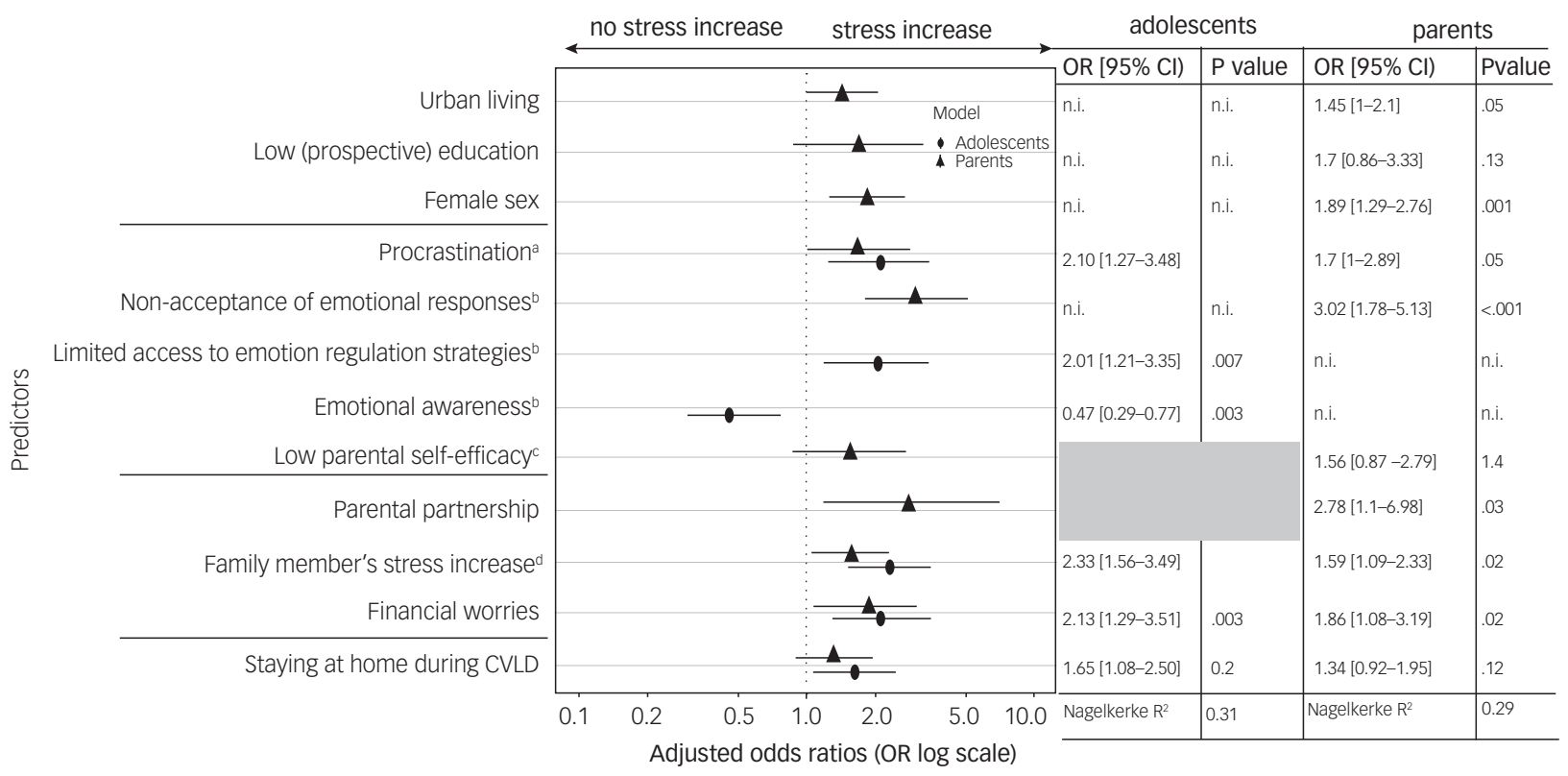

